\title{
EFFECTIVENESS OF MANNHEIM PERITONITIS INDEX SCORING SYSTEM IN PREDICTING THE MORBIDITY AND MORTALITY IN PERITONITIS DUE TO HOLLOW VISCUS PERFORATION
}

\author{
Shanta B. Patil1, Rashmi $D^{2}$, Vishweshvarayya ${ }^{3}$,Jagadish $M^{4}$
}

${ }_{1}^{1}$ Associate Professor, Department of General Surgery, MR Medical College, Kalaburagi, Karnataka, India.

2Postgraduate Student, Department of General Surgery, MR Medical College, Kalaburagi, Karnataka, India. 3 Postgraduate Student, Department of General Surgery, MR Medical College, Kalaburagi, Karnataka, India.

${ }_{4}^{4}$ Postgraduate Student, Department of General Surgery, MR Medical College, Kalaburagi, Karnataka, India.

\begin{abstract}
BACKGROUND

Peritonitis due to hollow viscus perforation is one of the common causes for emergency ward admission under surgery department. Its causes vary from the ones requiring immediate surgical intervention to those requiring conservative management. Its accurate diagnosis and management are a challenge to every surgeon. Scoring systems that provide objective descriptions of the patient's conditions at specific points in the disease process aid our understanding of these problems. Hence this study is undertaken to study the effectiveness of Mannheim's Peritonitis Index (MPI) in predicting the outcome in peritonitis patients who presented to Basaveshwara Teaching and General Hospital, Kalaburagi.
\end{abstract}

\section{MATERIALS AND METHODS}

This study is a clinical, prospective, observational and open study conducted at the department of General Surgery, Basaveshwar Teaching and General Hospital, Kalaburagi from July 2014 to March 2016. The sample size estimation was also done at convenience.

\section{RESULTS}

The mean age of the patients was 45.72 (SD 14.26) years. There was male preponderance (66\%) with male to female ratio of 1.9:1. In our study, the most common aetiology of peritonitis was duodenal perforation seen in $70 \%$ of patients, followed by gastric perforation (13\%), ileal (12\%), jejunal (3\%) and appendicular perforation (2\%).

\section{CONCLUSION}

Various factors like age, sex, duration, site of perforation, extent of peritonitis and delay in surgical intervention are associated with morbidity and mortality. MPI scoring system is the easiest score to apply. It helps in the determination of the risk during operation and also helps the surgeon know about the possible outcome and the appropriate management. MPI is more effective in predicting the mortality in peritonitis due to hollow viscus perforation.

\section{KEY WORDS}

Mannheim's Peritonitis Index, Peritonitis, Perforation.

HOW TO CITE THIS ARTICLE: Patil SB, Rashmi D, Vishweshvarayya, et al. Effectiveness of Mannheim peritonitis index scoring system in predicting the morbidity and mortality in peritonitis due to hollow viscus perforation. J. Evolution Med. Dent. Sci. 2018;7(44):4717-4720, DOI: $10.14260 /$ jemds/2018/1053

\section{BACKGROUND}

Peritonitis secondary to hollow viscus perforation is a potentially dangerous condition. Inspite of the advances in investigations and treatment the prognosis remains poor. Early diagnosis and surgery can improve the outcome.[1,2,3] Many scoring systems have been developed and used successfully to grade the severity of acute peritonitis like, Acute physiology and chronic health evaluation (APACHE) II score, Simplified acute physiology score (SAPS), Sepsis severity score (SSS), Ranson score, Imrie score, Mannheim peritonitis index (MPI).[4, 5]

'Financial or Other Competing Interest': None.

Submission 18-09-2018, Peer Review 11-10-2018,

Acceptance 17-10-2018, Published 29-10-2018.

Corresponding Author:

Dr. Rashmi $D$

\#87, $4^{\text {th }}$ Cross, $2^{\text {nd }}$ Stage,

Gruhalaxmi Layout,

Kamala Nagar,

Bengaluru-79,

Karnataka, India

E-mail: rashmi.dotihalkar@gmail.com

DOI: $10.14260 /$ jemds/2018/1053

\section{(c) (1) $(9)$}

Mannheim Peritonitis Index (MPI) is a specific score, which has a good accuracy and provides an easy way to handle with clinical parameters, allowing the prediction of the individual prognosis of patients with peritonitis.[6]

\section{Mannheim Peritonitis Index. $[7,8]$}

\begin{tabular}{|c|c|}
\hline Risk Factor & Weightage, if any \\
\hline Age $>$ 50 years & 5 \\
\hline Female Gender & 5 \\
\hline Organ Failure* & 7 \\
\hline Malignancy & 4 \\
\hline $\begin{array}{c}\text { Preoperative duration of peritonitis }>24 \\
\text { hours }\end{array}$ & 4 \\
\hline Origin of sepsis not colonic & 4 \\
\hline Diffuse generalised peritonitis & 6 \\
\hline Exudates & 0 \\
\hline Clear & 6 \\
\hline Cloudy, Purulent & 12 \\
\hline Faecal & \\
\hline
\end{tabular}

*Definitions of organ failure: Kidney: creatinine $>177$ $\mu \mathrm{mol} / \mathrm{L}$, urea $>167 \mu \mathrm{mol} / \mathrm{L}$, oliguria $<20 \mathrm{ml} / \mathrm{h}$; Lung: p02 $<50$ mmHg, pCO2 >50 mmHg; Shock: hypodynamic or 
hyperdynamic; Intestinal obstruction (only if profound): Paralysis $>24$ h or complete mechanical ileus.

\section{Aims and Objectives}

1. To study the validity of scoring system, presently being studied worldwide.

\section{These are-}
a. Mannheim Peritonitis Index.
b. Sepsis score of Elebute and Stoner.
c. APACHE-II.

2. To study the prognostic factors which determine the outcome of the disease.

\section{These are-}

\section{Patient Factors:}

a. Age of the patient.

b. Sex of the patient.

c. General health of the patient (i.e. nutrition, anaemia).

2. Disease Process:
a. Site of perforation.
b. Duration of perforation.
c. Extent of peritoneal contamination.

3. Effect of General Systemic Complications like:
a. Respiratory.
b. CVS system.
c. Shock.
d. Multi-organ failure.

Our aim was to study the effect of above factors on Mortality and Morbidity of the patients.

\section{MATERIALS AND METHODS}

Our study is a clinical, prospective, observational and open study conducted in 100 patients with peritonitis due to hollow viscus perforation who presented to Surgical Emergency, at Basaveshwar Teaching and General Hospital, Kalaburagi, from July 2016 to March 2018. The sample size estimation was also done at conveniences.

\section{Inclusion Criteria}

Patients with clinical suspicion and investigatory support for the diagnosis of peritonitis, due to hollow viscus perforation, who are later confirmed by intra-op findings.

\section{Various Aetiologies causing such Features Include}

1. Acid peptic disease.

2. Typhoid.

3. Tuberculosis.

4. Gangrenous bowel.

5. Appendicitis.

6. Malignancy.

\section{Exclusion Criteria} Patients with

1. Associated injuries to other organs.

2. Associated vascular, neurogenic injuries.

\section{Mode of Study}

The detailed history and proper clinical findings were entered in a proforma case sheet. Patients were subjected to a methodical physical examination to assess the general condition. Per abdomen examination was done and relevant findings were recorded. Rectal examination was done in all cases, per vaginal examination was also done in female patients.

The required and routine investigations were done to establish the diagnosis. Patients were asked to follow up after a specific interval or at recurrence of symptoms. MPI scoring system was done in all patients and patients were classified as those with a score less than 21, 21-27 and more than 27.

Preoperatively all patients received supportive treatment for correction of hypotension and electrolyte abnormalities. During laparotomy, intra-abdominal examination of all organs was made in addition to specific pathology. Primary closure of hollow viscus perforation was made in all cases with thorough peritoneal lavage and abdominal drains were kept in all patients. Patients were monitored in the postoperative period input-output charts and vital charts were maintained. Drains were removed after 48 hours and sutures were removed on the $7^{\text {th }}$ post-operative day. Most of the operated patients had uneventful recovery, 18 patients had morbidity in terms of wound infection and intensive care, 28 patients died.

The patients were followed up for a variable period of time.

\section{Method of Collection of Data}

The study is done after obtaining a detailed history, complete general physical examination and Systemic examination. The patients are subjected to relevant investigations like x-ray erect abdomen, CXR, USG and routine investigations like $\mathrm{Hb}$, $\mathrm{TC}$, urea, creatinine, serum electrolytes.

All investigations and surgical procedures were carried out with proper informed written consent as appropriately. The data regarding patient particulars, diagnosis, investigations and surgical procedures is collected in a specially designed case recording form and transferred to a master chart subjected to statistical methods like mean, standard deviation, proportion, percentage calculation and wherever necessary chi square test for proportion are used.

\section{RESULTS}

In this study, 100 cases of secondary and tertiary peritonitis who attended surgical emergency unit during the period of July 2014 to March 2016.

\begin{tabular}{|c|c|c|c|}
\hline Age (in Years) & Male (\%) & Female (\%) & Total (\%) \\
\hline Less than 15 & $0(0)$ & $1(100)$ & $1(1)$ \\
\hline $16-30$ & $11(68.8)$ & 5 (31.3) & $16(16)$ \\
\hline $31-45$ & $24(68.6)$ & $11(31.4)$ & $35(35)$ \\
\hline $46-60$ & $25(65.8)$ & $13(34.2)$ & $38(38)$ \\
\hline Above 60 & $6(60)$ & $4(40)$ & $10(10)$ \\
\hline Total & $66(66)$ & $34(34)$ & 100 \\
\hline
\end{tabular}

In the study, 100 patients with diagnosis of secondary peritonitis were included. The mean age of patients was 45.72(SD 14.26) years ranging from 13 to 75 and majority of patients (68.6\%) belonged to age group of 31-45 years. There was male preponderance $(66 \%)$ with male to female ratio of 1.9:1. 


\begin{tabular}{|c|c|c|c|}
\hline Duration & Mortality (\%) & Survival (\%) & Total (\%) \\
\hline 1 day & $1(7.1)$ & $13(92.9)$ & $14(14)$ \\
\hline 2-5 days & $21(26.9)$ & $57(73.1)$ & $78(78)$ \\
\hline $\begin{array}{c}\text { More than 5 } \\
\text { days }\end{array}$ & $6(75)$ & $2(25)$ & $8(8)$ \\
\hline Total & $\mathbf{2 8}$ & $\mathbf{7 2}$ & $\mathbf{1 0 0}$ \\
\hline \multicolumn{4}{|c|}{ Table 2. Time of Presentation of Study Subjects } \\
\hline
\end{tabular}

Chi square value -11.83 , $\mathrm{p}$ value -0.003

In the study group of 100 patients, majority of the patients (86\%) presented to the hospital after 24 hours of the onset of symptoms and the mortality of those patient who presented within 2-5 days and after 5 days was $26.9 \%$ and $75 \%$ respectively as compared to mortality $(7.1 \%)$ in patients who presented on the first day of onset of symptoms. The chi square value of these patients is 11.83 with a significant pvalue of 0.003 .

\begin{tabular}{|c|c|c|c|c|}
\hline MPI Score & Dead (\%) & WI (\%) & Survivors (\%) & Total (\%) \\
\hline$<21$ & $0(0)$ & $3(5.8)$ & $49(94.2)$ & $52(52)$ \\
\hline $21-27$ & $12(41.4)$ & $12(41.4)$ & $5(17.2)$ & $29(29)$ \\
\hline$>27$ & $16(84.2)$ & $3(15.8)$ & $0(0)$ & $19(19)$ \\
\hline Total & $\mathbf{2 8}(\mathbf{2 8 )}$ & $\mathbf{1 8}(18)$ & $\mathbf{5 4}(54)$ & $\mathbf{1 0 0}$ \\
\hline \multicolumn{6}{|c|}{ Table 3. Distribution of Study Subjects and MPI Score } \\
\hline
\end{tabular}

Chi square value -84.13 , p-value -0.000 .

In the study group of 100 patients, $52 \%$ of the patients had an MPI score of less than 21, of which 5.8\% developed wound infection (WI) with $0 \%$ mortality and $94.2 \%$ of the patients being normal. $29 \%$ patients had an MPI score between $21-27$, out of which $41.4 \%$ had morbidity (Wound infection) and the mortality rate was $41.4 \%$. in the patients with MPI score $>27$, the morbidity rate was $15.8 \%$ and the mortality rate was $84.2 \%$. The Chi square value is 84.13 with significant p-value of 0.000 .

\begin{tabular}{|c|c|c|c|}
\hline MPI score & WI & NORMAL & TOTAL \\
\hline$\geq 21$ & $15(75)$ & $5(25)$ & $20(27.8)$ \\
\hline$<21$ & $3(5.7)$ & $49(94.3)$ & $52(72.2)$ \\
\hline Total & 18 (25) & 54 (75) & $\mathbf{7 2}(\mathbf{1 0 0})$ \\
\hline \multicolumn{4}{|c|}{ Table 4. Morbidity and MPI Score } \\
\hline
\end{tabular}

PPV- 75\%, sensitivity- 83.33\%, specificity- 90.74\%.

In the study group, $75 \%$ of the patients had wound infection (Morbidity) with MPI score more than 21 as compared to $5.7 \%$ of the patients with MPI score less than 21 . The positive predictive value of MPI score for morbidity is $75 \%$ with sensitivity $-83.33 \%$ and specificity $-90.74 \%$.

\begin{tabular}{|c|c|c|c|}
\hline MPI Score & Mortality & Normal & Total \\
\hline$\geq 21$ & $28(84.8)$ & $5(15.2)$ & $33(40.3)$ \\
\hline$<21$ & $0(0)$ & $49(100)$ & $49(59.7)$ \\
\hline Total & $\mathbf{2 8 ~ ( 3 4 . 1 )}$ & 54 (65.9) & $\mathbf{8 2}(\mathbf{1 0 0})$ \\
\hline \multicolumn{3}{|c|}{ Table 5. Mortality and MPI Score } \\
\hline
\end{tabular}

PPV $-84.8 \%$, sensitivity $-100 \%$, specificity $-90.74 \%$.

In the study group, $84.8 \%$ of the patients had mortality among patients with MPI score more than or equal to 21 and none of the patients died with MPI score less than 21 . The positive predictive value for mortality is $84.8 \%$ with sensitivity $100 \%$ and specificity $90.74 \%$.

\begin{tabular}{|c|c|c|c|}
\hline Aetiology & MPI <21 (\%) & MPI $\geq 21(\%)$ & Total \% \\
\hline Appendicular & $1(50)$ & $1(50)$ & $2(2)$ \\
\hline Duodenal & $41(58.6)$ & $29(41.4)$ & $70(70)$ \\
\hline Gastric & $7(53.8)$ & $6(46.2)$ & $13(13)$ \\
\hline Ileal & $1(8.3)$ & $11(91.7)$ & $12(12)$ \\
\hline Jejunal & $2(66.7)$ & $1(33.3)$ & $3(3)$ \\
\hline Total & $52(52)$ & $\mathbf{4 8}(\mathbf{4 8 )}$ & $\mathbf{1 0 0 ( 1 0 0 )}$ \\
\hline \multicolumn{4}{|c|}{ Table 6. Aetiology and MPI Score } \\
\hline
\end{tabular}

Chi square value -10.65 , df -4 , p-value -0.03 .

In the study population of 100 subjects, duodenal perforation was seen in $70 \%$ of the patients, followed by gastric perforation (13\%), ileal (12\%), jejunal $(3 \%)$ and appendicular perforation (2\%) as the aetiologies of peritonitis. Among the patients with ileal perforation $(12 \%)$ $91.7 \%$ of them had an MPI score more than 21 . The Chi square value is 10.65 and p-value is 0.03 which is significant.

\section{CHART SHOWING ETIOLOGICAL DISTRIBUTION}

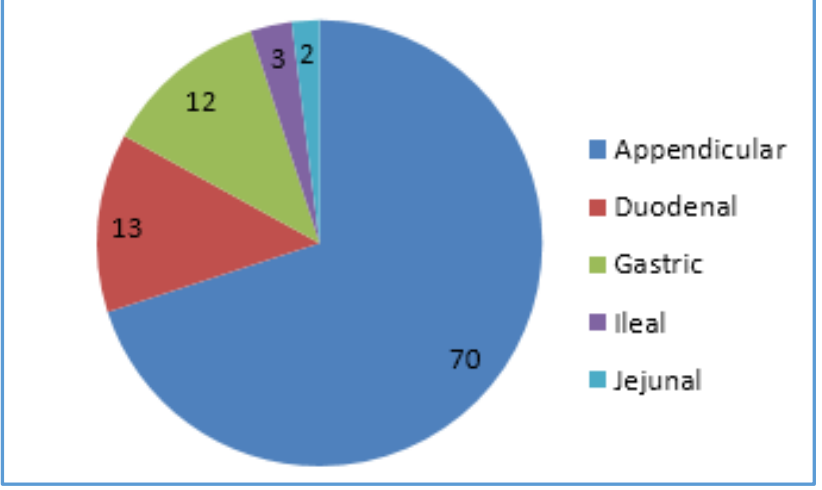

Figure 1

\section{DISCUSSION}

Peritonitis following hollow viscus perforation is one of the commonest reasons for emergency surgery. Various factors like age, sex, organ failure, malignancy, extent of peritonitis, type of contamination, site of perforation, surgical interventions, all affect mortality and morbidity. Effective preoperative management, timely surgery and appropriate post-operative care will determine the outcome.

Different studies have mortalities ranging from $6.4 \%$ to $17.5 \%$. According to the literature MPI is an independent, objective and effective scoring system in predicting mortality and has advantages over the other scoring systems. $[9,10]$

In the present study, 100 cases of peritonitis, those attending BTGH emergency from July 2014 to March 2016 were included with age ranging from 13 to 75 years. The mean age of the patients was 45.72 (SD 14.26) years. There was a male preponderance $(66 \%)$ with male to female ratio of 1.9:1. In our study, the most common aetiology of peritonitis was duodenal perforation seen in $70 \%$ of the patients, followed by gastric perforation (13\%), ileal (12\%), jejunal (3\%) and appendicular perforation (2\%). 


\section{CONCLUSION}

1. Peritonitis remains a hot spot for the surgeons despite advancements in surgical techniques and intensive care treatment. Various factors like age, sex, duration, site of perforation, extent of peritonitis and delay in surgical intervention are associated with morbidity and mortality.

2. Duodenal perforation is the most common aetiology of peritonitis followed by gastric, ileal, jejunal and appendicular perforation.

3. Males are commonly affected compared to females.

4. Emergency laparotomy and primary repair of the hollow viscus perforation is more effective in patients with secondary and tertiary peritonitis.

5. There is no significant difference in prognostic value between the MPI and APACHE II scoring systems.

6. In the management of patients with generalised peritonitis, scoring the patients into various risk groups can be beneficial.

7. MPI scoring system is easiest to apply; the determination of risk is available during operation and surgeon can know about the possible outcome and the appropriate management can be decided.

8. MPI is more effective in predicting the mortality in peritonitis due to hollow viscus perforation.

\section{REFERENCES}

[1] Bohnen J, Boulanger M, Meakins JL, et al. Prognosis in generalized peritonitis: relation to cause and risk factors. Arch Surg 1983;118(3):285-90.

[2] Giessling U, Petersen S, Freitag M, et al. Surgical management of severe peritonitis. Zentralbl Chir 2002;127(7):594-7.
[3] Farthmann EH, Schoffel U. Principles and limitations of operative management of intra-abdominal infections. World J Surg 1990;14(2):210-7.

[4] Kologlu M, Elker D, Altun H, et al. Validation of MPI and PIA II in two different groups of patients with secondary peritonitis. Hepatogastroenterology 2001;48(37):147-51.

[5] Bosscha K, Reijnders K, Hulstaert PF, et al. Prognostic scoring systems to predict outcome in peritonitis and intra-abdominal sepsis. Br J Surg 1997;84(11):1532-4.

[6] Correia MM, Thuler LCS, Velasco E, et al. Prediction of death using the Mannheim. Peritonitis Index in oncologic patients. Revista Brasileira de Cancerologia 2001;47(1):63-8.

[7] Wacha H, Linder MM, Feldman U, et al. Mannheim peritonitis index - prediction of risk of death from peritonitis: construction of a statistical and validation of an empirically based index. Theoretical Surg 1987;1(4):169-77.

[8] Billing A, Fröhlich D, Schildberg FW. Prediction of outcome using the Mannheim peritonitis index in 2003 patients. Peritonities Study Group. Br J Surg 1994;81(2):209-13.

[9] Notash AY, Salimi J, Rahimian H, et al. Evaluation of Mannheim peritonitis index and multiple organ failure score in patients with peritonitis. Indian Journal of Gastroenterology 2005;24(5):197-200.

[10] Demmel N, Muth G, Maag K, et al. Prognostic scores in peritonitis: the Mannheim Peritonitis Index or APACHE II? Langenbecks Arch Chir 1994;379(6):34752. 